\title{
Prevalence and correlates of binge eating disorder related features in the community
}

\author{
Linda Mustelin $^{\text {a, b, d, * , Cynthia M. Bulik }}{ }^{\text {b, c }}$, Jaakko Kaprio a, d, Anna Keski-Rahkonen ${ }^{\text {a }}$ \\ a Department of Public Health, University of Helsinki, Finland \\ b Departments of Psychiatry and Nutrition, University of North Carolina at Chapel Hill, Chapel Hill, NC, USA

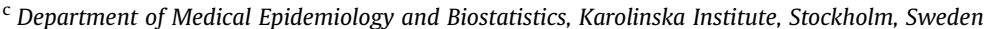 \\ ${ }^{\mathrm{d}}$ Institute for Molecular Medicine Finland FIMM, University of Helsinki, Helsinki, Finland
}

\section{A R T I C L E I N F O}

\section{Article history:}

Received 6 July 2016

Received in revised form

19 November 2016

Accepted 23 November 2016

Available online 27 November 2016

\section{Keywords:}

Eating behavior

Disordered eating

Binge eating

Body mass index

Longitudinal cohort study

Weight gain

Psychological distress

\begin{abstract}
A B S T R A C T
Binge eating disorder (BED) is associated with high levels of obesity and psychological suffering, but little is known about 1) the distribution of features of BED in the general population and 2) their consequences for weight development and psychological distress in young adulthood. We investigated the prevalence of features of BED and their association with body mass index (BMI) and psychological distress among men $(n=2423)$ and women $(n=2825)$ from the longitudinal community-based FinnTwin 16 cohort (born 1975-1979). Seven eating-related cognitions and behaviors similar to the defining features of BED were extracted from the Eating Disorder Inventory-2 and were assessed at a mean age of 24. BMI and psychological distress, measured with the General Health Questionnaire, were assessed at ages 24 and 34. We assessed prevalence of the features and their association with BMI and psychological distress cross-sectionally and prospectively. More than half of our participants reported at least one feature of BED; clustering of several features in one individual was less common, particularly among men. The most frequently reported feature was 'stuffing oneself with food', whereas the least common was 'eating or drinking in secrecy'. All individual features of BED and their clustering particularly were associated with higher BMI and more psychological distress cross-sectionally. Prospectively, the clustering of features of BED predicted increase in psychological distress but not additional weight gain when baseline BMI was accounted for. In summary, although some features of BED were common, the clustering of several features in one individual was not. The features were cumulatively associated with BMI and psychological distress and predicted further increase in psychological distress over ten years of follow-up.
\end{abstract}

(c) 2016 Published by Elsevier Ltd.

\section{Introduction}

Binge eating is a form of disordered eating, defined as eating large quantities of food accompanied by a sense of loss of control. It is often triggered by negative emotions and followed by feelings of guilt and shame (Haedt-Matt \& Keel, 2011; Leehr et al., 2015; Munsch, Meyer, Quartier, \& Wilhelm, 2012). When binge eating is regular and accompanied by additional features, such as distress, eating alone due to embarrassment, and feeling very guilty afterward, diagnostic criteria for binge eating disorder (BED) are met (American Psychiatric Association, 2013).

* Corresponding author. Department of Public Health, University of Helsinki, P.O. Box 20, Biomedicum 2B, 5th floor, Tukholmankatu 8, 00014 University of Helsinki, Finland.

E-mail address: linda.mustelin@helsinki.fi (L. Mustelin).
The population prevalence of clinical BED is $<1 \%-3.5 \%$ (Hudson, Hiripi, \& Pope HGKessler, 2007; Kessler et al., 2013; Mustelin, Raevuori, Hoek, Kaprio, \& Keski-Rahkonen, 2015; Preti et al., 2009; Smink, van Hoeken, Oldehinkel, \& Hoek, 2014), but up to $15 \%$ of adolescents and young adults report some loss of control or binge eating (Abebe, Lien, Torgersen, \& von Soest, 2012; Goldschmidt et al., 2015; Sonneville et al., 2013), the core behavioral feature of BED. Eating alone and experiencing secrecy (Tanofsky-Kraff et al., 2007) and negative emotions both preceding and following eating (Goldschmidt, Crosby, Cao et al., 2014; HaedtMatt \& Keel, 2011) have been shown to associate with loss of control and binge eating, but how common such associated behaviors and cognitions are in the community is not yet known.

Clinical BED is associated with high levels of obesity (StriegelMoore et al., 2001; de Zwaan, 2001) and psychiatric comorbidity, particularly major depression (Grilo, White, \& Masheb, 2009; Javaras et al., 2008; Mustelin et al., 2015; Striegel-Moore et al., 
2001). The behavioral component of BED, binge eating, is also associated both with long-term weight gain and depressive symptoms (Sonneville et al., 2013; Tanofsky-Kraff et al., 2009, 2011). Less is known about the accompanying behaviors and cognitions and how they relate to body weight and psychological distress in the population at whole.

We investigated seven eating-related behaviors and cognitions similar to the defining features of BED (American Psychiatric Association, 2013) in a community sample of young adults. The investigated traits, hereafter referred to as 'features of BED', included the defining behavioral characteristics of binge eating overeating and a sense of loss of control (Wolfe, Baker, Smith, \& Kelly-Weeder, 2009) - but also associated features, such as eating alone due to embarrassment and negative feelings associated with eating episodes.

The aims of this study were to explicate 1 ) how common features of BED are in a population-based cohort of young adults, 2) how they cluster together in individuals, and 3) whether individual features or their clustering are associated with BMI or psychological distress cross-sectionally or prospectively over 10 years. We hypothesized that endorsing only one or two features would be relatively harmless, but that endorsing several features would be associated with weight gain and psychological distress.

\section{Subjects and methods}

\subsection{FinnTwin16 birth cohorts}

This nationwide longitudinal cohort study of health behaviors in twins and their families (Kaprio, Pulkkinen, \& Rose, 2002) identified twin births in 1975-79 from the central population register of Finland. The FinnTwin16 cohort was restricted to those pairs who were alive and resided in Finland at age 16. Data collection and analysis were approved by the ethics committee of the Department of Public Health of University of Helsinki.

The twins and their parents were sent baseline self-report questionnaires when the twins were $16 \mathrm{y}$ (Wave 1). Follow-up questionnaires were mailed to the twins when they were $17 \mathrm{y}$ (Wave 2), 18 y (Wave 3), 22-27 y (Wave 4), and finally 31-37 y (Wave 5). The cohort and Waves of data collection have been previously described in detail (Kaprio, 2006, 2013; Kärkkäinen, Mustelin, Raevuori, Kaprio, \& Keski-Rahkonen, 2016). The analyses in the present study were restricted to individuals who participated in Wave 4 (2825 women and 2423 men), when disordered eating was assessed. Of them, 74\% participated in Wave 5 .

\subsection{Assessment of features of binge eating disorder}

The Wave 4 questionnaire included three subscales of the Eating Disorder Inventory-2 (EDI): Bulimia, Drive for Thinness, and Body Dissatisfaction (Garner, 1991). In this study we focused on seven items similar to the defining features of BED (American Psychiatric Association, 2013): six items from the Bulimia subscale: 'I eat when I'm upset', 'I stuff myself with food', 'I have gone on eating binges where I have felt that I could not stop', 'I think about bingeing (overeating)', 'I eat moderately in front of others and stuff myself when they're gone', 'I eat or drink in secrecy' and one item from the Drive for Thinness subscale: 'I feel extremely guilty after overeating'. Each item was scored on a 5-point Likert scale ranging from 'never' to 'always'. Internal consistency of the resulting 7-item scale was good (Cronbach's alpha $=0.802$ ). The timeframe for the endorsement of the items was not specified, but questions were in present tense.
To estimate prevalences of features of BED and group individuals according to presence or absence of each feature, we dichotomized each item so that subjects were defined as positive if they reported it either sometimes, often, usually, or always, and negative if their answer was 'rarely' or 'never'.

To assess the cumulative number of features of BED, we created a summary score summing the total number of positive items the participants reported. Because of the small number of individuals reporting all seven behaviors, we combined the two uppermost categories. The resulting summary score had seven categories ranging from 'no features' to 'six or seven features'.

\subsection{Assessment of BMI}

We calculated BMI from self-reported height and weight at Wave $4(22-27 \mathrm{y})$, and Wave 5 (31-37 y). In the whole cohort, as previously reported, mean BMI at Wave 4 was $22.2 \mathrm{~kg} / \mathrm{m}^{2}$ (SD 3.5) for women and 23.9 (SD 3.1) for men. At Wave 5, the respective mean BMIs were 23.5 (SD 4.6) and 25.7 (SD 3.7) (Kärkkäinen et al., 2016).

\subsection{Assessment of psychological distress}

Psychological distress was measured with the 12-item General Health Questionnaire (GHQ-12) using four-point Likert scoring (01-2-3) (Goldberg et al., 1997; Penninkilampi-Kerola, Miettunen, \& Ebeling, 2006). The internal consistency of the scale was good both at age 24y (Cronbach's alpha 0.86) and 34y (Cronbach's alpha 0.87).

\subsection{Statistical analyses}

We estimated prevalences and 95\% confidence intervals for each individual feature of BED and calculated mean BMI at age 24 and 34 for those endorsing and not endorsing each feature at age 24 . We used Pearson correlation to investigate how the features were intercorrelated and calculated the proportions of participants endorsing different numbers of features.

We used ordinary least-squares linear regression to estimate how the number of features of BED at age 22-27 was associated with BMI and psychological distress. We examined a) their crosssectional relationship at Wave 4 and b) whether Wave 4 bingeeating summary score predicted 10-year change (delta) in psychological distress independent of baseline psychological distress, BMI, and BMI change. Because of the different distributions of the binge eating features and their clustering among women and men in the cohort, we conducted all analyses separately for women and men. Very few participants $(<1 \%-3 \%)$, were missing data for the used variables; we therefore performed a complete-case analysis (Langkamp, Lehman, \& Lemeshow, 2010). We found no evidence of selective attrition in respect to features of BED between Waves 4 and 5 (full attrition analysis available from the authors). To account for correlation within twin pairs, we used robust variance estimation for clustered data (Williams, 2000). All analyses were conducted using Stata 13.

\section{Results}

\subsection{Prevalence and distribution of features of binge eating disorder}

After exclusion of 121 individuals missing data on any feature of BED, our analyses included 5137 individuals (2762 women and 2375 men). The distributions of each individual binge-eating feature among women and men are presented in Fig. 1. Of the dichotomized items, the most common was 'stuffing oneself with food'; $45 \%$ of women and $49 \%$ of men reported doing it at least 

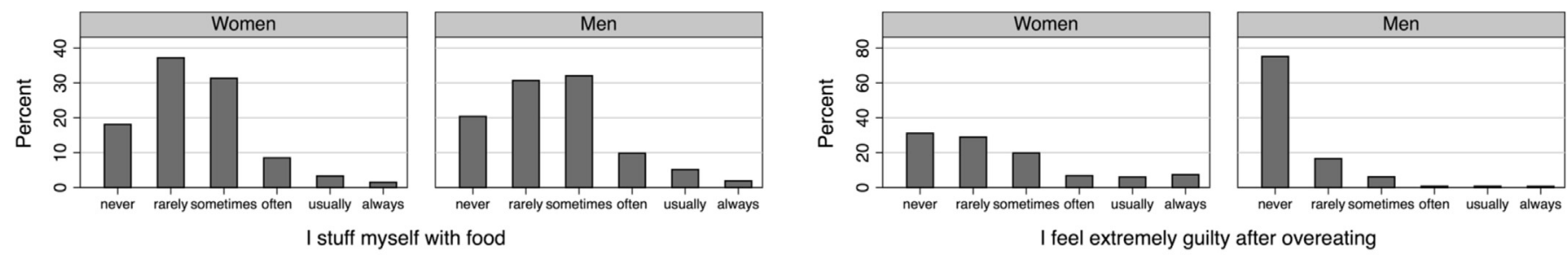

I feel extremely guilty after overeating
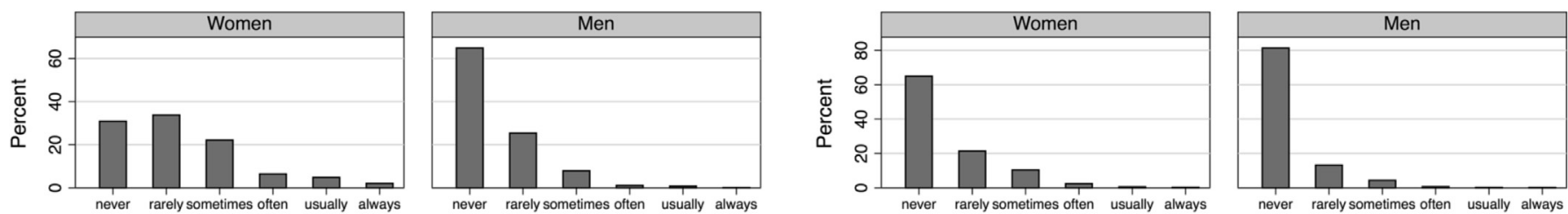

I eat when I'm upset

I have gone on eating binges where I have felt that I could not stop
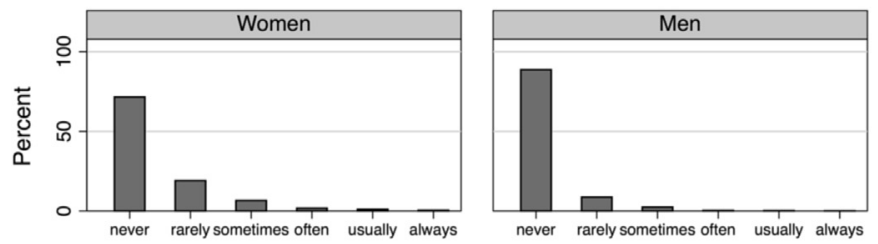

I eat moderately in front of others and stuff myself when they're gone
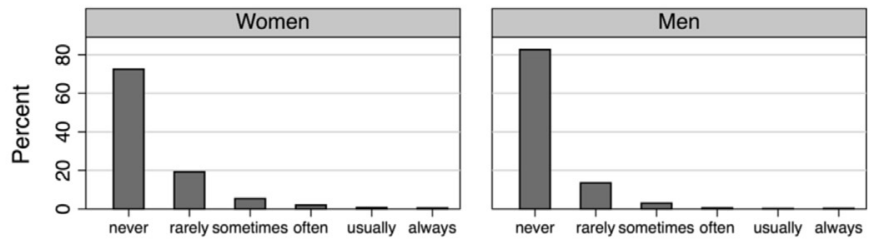

I think about bingeing
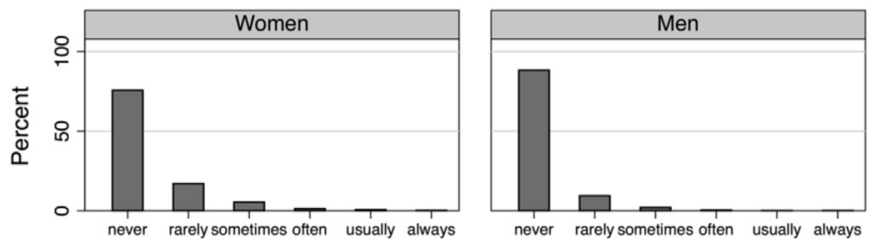

I eat or drink in secrecy

Fig. 1. Distributions of the individual features of binge eating disorder in the study population at Wave 4 (mean age 24).

sometimes (Table 1). The least common feature reported both among women and men was, 'eating or drinking in secrecy' (7.4\% and $2.5 \%$, respectively). All features except 'stuffing oneself with food' were more common among women than men, with the largest differences observed in 'feeling extremely guilty after overeating' and 'eating when upset' (Table 1).

Table 1

BMI at mean age 24 and 34 among those reporting each of the seven features of binge eating disorder (BED).

\begin{tabular}{|c|c|c|c|c|c|c|c|c|c|c|c|}
\hline \multirow{2}{*}{ Feature of $B E D^{a}$} & \multirow{2}{*}{\multicolumn{3}{|c|}{$\begin{array}{l}\text { Number and } \\
\text { proportion of } \\
\text { women and } \\
\text { men positive } \\
\text { for each feature }\end{array}$}} & \multicolumn{4}{|c|}{ BMI at age $22-27$} & \multicolumn{4}{|c|}{ BMI at age $31-37$} \\
\hline & & & & \multicolumn{2}{|c|}{$\begin{array}{l}\text { Endorsing } \\
\text { feature }\end{array}$} & \multicolumn{2}{|c|}{$\begin{array}{l}\text { Not endorsing } \\
\text { feature }\end{array}$} & \multicolumn{2}{|c|}{$\begin{array}{l}\text { Endorsing } \\
\text { feature }\end{array}$} & \multicolumn{2}{|c|}{$\begin{array}{l}\text { Not endorsing } \\
\text { feature }\end{array}$} \\
\hline \multicolumn{12}{|l|}{ Women } \\
\hline & $n$ & $\%$ & $95 \% C I$ & mean & $95 \% \mathrm{CI}$ & mean & $95 \% C I$ & mean & $95 \% \mathrm{CI}$ & mean & $95 \% C I$ \\
\hline I stuff myself with food & 1250 & 44.7 & $42.7,46.6$ & 23.8 & $23.4,24.2$ & 22.0 & $21.9,22.2$ & 25.8 & $25.1,26.5$ & 23.7 & $23.5,23.9$ \\
\hline I feel extremely guilty after overeating & 1121 & 39.9 & $38.0,41.9$ & 23.5 & $23.2,23.8$ & 21.9 & $21.8,22.1$ & 25.3 & $24.7,25.9$ & 23.6 & $23.4,23.9$ \\
\hline I eat when I'm upset & 996 & 35.4 & $33.6,37.3$ & 23.7 & $23.3,24.1$ & 22.0 & $21.9,22.2$ & 25.9 & $25.2,26.6$ & 23.7 & $23.5,23.9$ \\
\hline I have gone on eating binges where I have felt that I could not stop & 385 & 13.7 & $12.4,15.1$ & 23.6 & $22.7,24.4$ & 22.2 & $22.1,22.4$ & 25.0 & $23.5,26.6$ & 23.9 & $23.7,24.2$ \\
\hline I eat moderately in front of others and stuff myself when they're gone & 269 & 9.6 & $8.5,10.8$ & 25.0 & $24.1,25.8$ & 22.2 & $22.0,22.3$ & 26.6 & $24.8,28.5$ & 23.9 & $23.7,24.1$ \\
\hline I think about bingeing (overeating) & 233 & 8.3 & $7.3,9.4$ & 24.8 & $23.9,25.7$ & 22.2 & $22.0,22.3$ & 26.7 & $24.5,28.9$ & 23.9 & $23.7,24.1$ \\
\hline I eat or drink in secrecy & 208 & 7.4 & $6.5,8.5$ & 25.1 & $24.1,26.2$ & 22.2 & $22.0,22.3$ & 26.9 & $24.9,29.0$ & 23.9 & 23.9 \\
\hline & $n$ & $\%$ & $95 \% C I$ & mean & $95 \% C I$ & mean & $95 \% C I$ & mean & $95 \% C I$ & mean & $95 \% C I$ \\
\hline I stuff myself with food & 1175 & 48.9 & $46.8,51.0$ & 24.6 & $24.3,25.0$ & 23.7 & $23.6,23.8$ & 26.9 & $26.3,27.5$ & 25.5 & $25.3,25.7$ \\
\hline I feel extremely guilty after overeating & 198 & 8.3 & $7.2,9.5$ & 26.3 & $25.3,27.3$ & 23.8 & $23.7,24.0$ & 28.3 & $26.2,30.4$ & 25.7 & $25.5,25.9$ \\
\hline I eat when I'm upset & 237 & 9.9 & $8.7,11.2$ & 26.1 & $25.0,27.1$ & 23.8 & $23.7,24.0$ & 29.4 & $25.9,33.0$ & 25.7 & $25.5,25.9$ \\
\hline I have gone on eating binges where I have felt that I could not stop & 132 & 5.5 & $4.6,6.5$ & 25.9 & $24.4,27.3$ & 23.9 & $23.7,24.0$ & 30.7 & $25.4,36.0$ & 25.7 & $25.5,25.9$ \\
\hline I eat moderately in front of others and stuff myself when they're gone & 68 & 2.8 & $2.2,3.6$ & 27.0 & $24.6,29.4$ & 23.9 & $23.7,24.0$ & 30.4 & $25.2,35.7$ & 25.7 & $25.5,25.9$ \\
\hline I think about bingeing (overeating) & 94 & 3.9 & $3.2,4.8$ & 27.1 & $25.5,28.7$ & 23.9 & $23.7,24.0$ & 30.9 & $26.6,35.2$ & 25.7 & $25.5,25.9$ \\
\hline I eat or drink in secrecy & 59 & 2.5 & $1.9,3.2$ & 26.3 & $23.8,28.9$ & 23.9 & $23.7,24.0$ & 27.2 & $23.2,31.2$ & 25.7 & $25.5,25.9$ \\
\hline
\end{tabular}

\footnotetext{
a Dichotomized as at least sometimes (vs. rarely or never).
}

b At mean age 24 . 


\subsection{Clustering of features of binge eating disorder}

Women were more likely than men to report several features of BED: $67 \%$ of women and $56 \%$ of men reported at least one positive item, whereas $23 \%$ of women and $5.9 \%$ of men reported three or more. Six or seven items were reported by $3.9 \%(n=108)$ of the women and only $0.25 \%(n=6)$ of the men. Fig. 2 presents the distributions of summary scores in women and men. The correlation matrix of the features (Table 2) shows that having gone on eating binges and thinking about binge eating were most frequently reported by the same individuals, whereas stuffing oneself with food and eating or drinking in secrecy had the lowest correlation.

\subsection{Association of features of binge eating disorder with BMI}

BMI and features of BED were consistently associated with each other. In simple bivariate analyses, each of the seven features of BED was associated with BMI both cross-sectionally at age 24 and prospectively at age 34 , so that individuals who endorsed each feature had higher mean BMI than those who did not. This was true for both women and men (Table 1).

The total number of features represented by the summary score was associated with BMI in a cumulative manner: the more features the participants reported, the higher their mean BMI. This was true both cross-sectionally at age 24 (Fig. 2) and prospectively, at age $34(\beta=0.57, \mathrm{t}=7.49, \mathrm{p}<0.001$ for women and $\beta=0.84$, $\mathrm{t}=4.50, \mathrm{p}<0.001$ for men). At age 24 , the difference in mean BMI between participants endorsing only one feature and those endorsing 6-7 features was approximately two BMI units among women and ten BMI units among men. Fig. 3 shows how BMI developed over 10 years of follow-up according to number of endorsed features at age 24 . Even though those with more features had consistently higher BMI, the summary score was not a significant predictor of 10 -year weight change either in women $(\beta=0.02$, $\mathrm{t}=0.38, \mathrm{p}=0.70)$ or men $(\beta=0.19, \mathrm{t}=1.71, \mathrm{p}=0.09)$. This means that the weight trajectories of individuals with different numbers of features of BED had already diverged before age 24 .

\subsection{Association with psychological distress}

Psychological distress was measured with the GHQ-12 score that ranges from 0 to 36 . The mean GHQ-12 score for women was 11.3 (standard deviation 5.6) at age $22-27$ years and $11.2(5.7)$ ten years later. The respective scores for men were 9.7 (4.7) and 10.3 (5.2). The number of features of BED was associated with more psychological distress at age 22-27, even after controlling for BMI. This was true for both women $(\beta=1.01, \mathrm{t}=15.5, \mathrm{p}<0.001)$ and men $(\beta=1.03, \mathrm{t}=10.3, \mathrm{p}<0.001)$.

Psychological distress also increased more over ten years (from mean age 24 to 34) among individuals endorsing more features of BED. The association between number of features (explanatory variable) and 10-year change in psychological distress (outcome variable) was positive both among women $(\beta=0.27, \mathrm{t}=3.3$, $\mathrm{p}=0.001)$ and men $(\beta=0.36, \mathrm{t}=2.5, \mathrm{p}=0.014)$ in a multivariable model controlling for Wave 4 psychological distress and BMI as well as the 10-year change in BMI.

\section{Discussion}

We studied the prevalence and correlates of features of BED in a longitudinal, population-based cohort of young adult women and men. More than half of our population endorsed at least one feature. Clustering of several features in one individual was considerably less common, particularly among men, but both women and men reporting clustering of features in their midtwenties had consistently higher BMI in their mid-twenties and -thirties. The clustering of features of BED was also associated with higher levels of psychological distress cross-sectionally and prospectively. In summary, BED-related behaviors and cognitions were cumulatively associated with both BMI and psychological distress in the community.

We examined a spectrum of eating-related behaviors and cognitions similar to the defining features of BED, including indicators

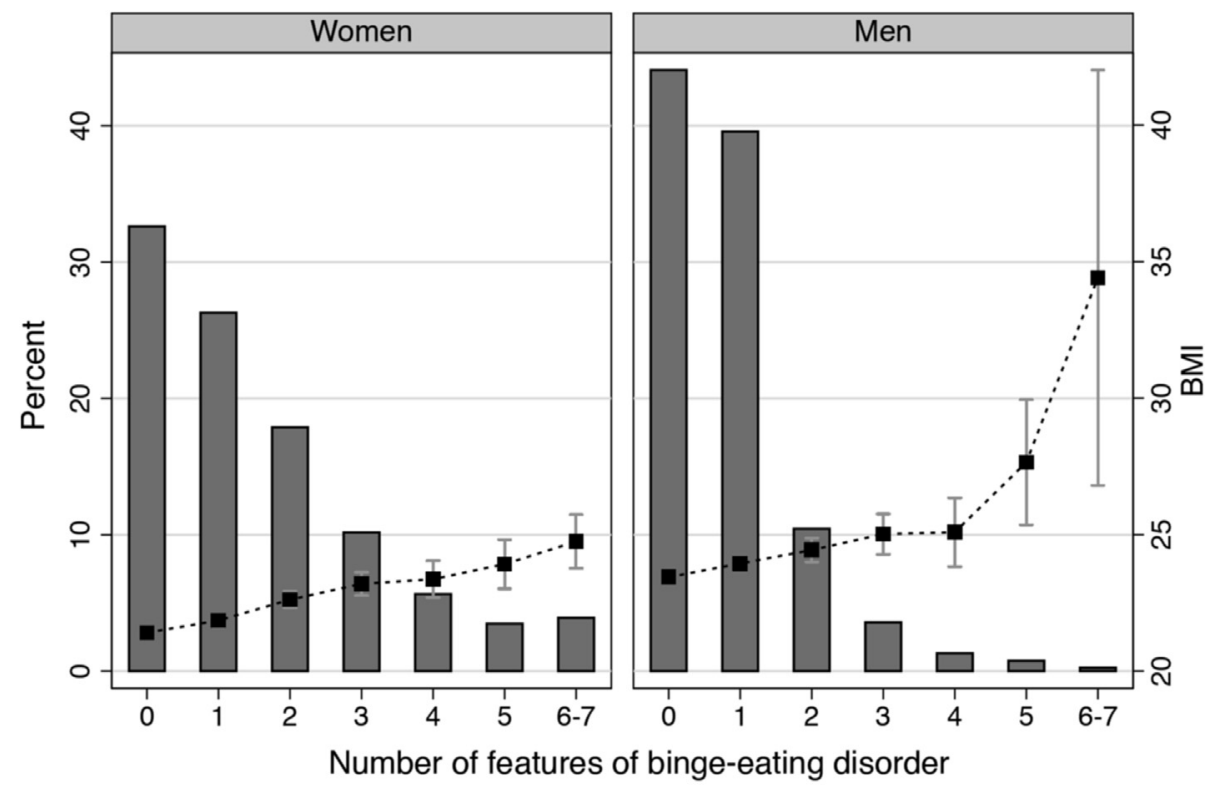

.......... Mean BMI

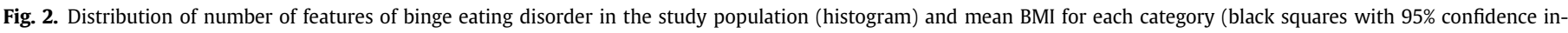
tervals) at Wave 4 (mean age 24). 
Table 2

Correlation matrix of the features of binge eating disorder at mean age 24 .

\begin{tabular}{|c|c|c|c|c|c|c|c|}
\hline Feature of binge eating disorder & A. & B. & C. & D. & E. & F. & G. \\
\hline \multicolumn{8}{|l|}{ Women } \\
\hline A. I stuff myself with food & 1 & & & & & & \\
\hline B. I feel extremely guilty after overeating & 0.41 & 1 & & & & & \\
\hline C. I eat when I'm upset & 0.46 & 0.42 & 1 & & & & \\
\hline D. I have gone on eating binges where I have felt that I could not stop & 0.48 & 0.46 & 0.43 & 1 & & & \\
\hline E. I eat moderately in front of others and stuff myself when they're gone & 0.41 & 0.44 & 0.38 & 0.49 & 1 & & \\
\hline F. I think about bingeing (overeating) & 0.45 & 0.49 & 0.44 & 0.62 & 0.54 & 1 & \\
\hline G. I eat or drink in secrecy & 0.34 & 0.40 & 0.39 & 0.46 & 0.59 & 0.52 & 1 \\
\hline \multicolumn{8}{|l|}{ Men } \\
\hline A. I stuff myself with food & 1 & & & & & & \\
\hline B. I feel extremely guilty after overeating & 0.18 & 1 & & & & & \\
\hline C. I eat when I'm upset & 0.22 & 0.33 & 1 & & & & \\
\hline D. I have gone on eating binges where I have felt that I could not stop & 0.31 & 0.29 & 0.23 & 1 & & & \\
\hline E. I eat moderately in front of others and stuff myself when they're gone & 0.17 & 0.28 & 0.24 & 0.27 & 1 & & \\
\hline F. I think about bingeing (overeating) & 0.26 & 0.36 & 0.27 & 0.46 & 0.33 & 1 & \\
\hline G. I eat or drink in secrecy & 0.16 & 0.26 & 0.24 & 0.27 & 0.35 & 0.29 & 1 \\
\hline
\end{tabular}

Values are Pearson correlation coefficients calculated using Likert-scored Eating Disorder Inventory items.

of impaired control and associated negative emotions. Despite being the most common eating disorder in many settings (Hudson et al., 2007; Smink et al., 2014), interview-ascertained DSM-5 BED only affected $0.7 \%$ of the women in our cohort, according to a previous study of the same sample (Mustelin et al., 2015). In contrast, a total of $13.7 \%$ of women and $5.5 \%$ of men in our cohort reported having gone on eating binges. The prevalence estimates of all features of BED varied by sex and ranged from $<5 \%$ to almost 50\%: 'stuffing oneself with food' was the most common feature in our setting ( $45 \%$ of women and $49 \%$ of men), whereas 'eating or drinking in secrecy' was the most infrequently endorsed $(7.4 \%$ of women and $2.5 \%$ of men). Our results are in line with previous reports on prevalence of binge eating and loss of control eating (Abebe et al., 2012; Abraham, Massaro, Hoffmann, Yanovski, \& Fox, 2014; Goldschmidt et al., 2015; Hay, Mond, Buttner, \& Darby, 2008; Hudson et al., 2007; Sonneville et al., 2013), and complemented them by investigating a broader range of related behaviors and cognitions.
Various forms of disordered eating and loss of control have been shown to associate with weight gain and obesity (Darby, Hay, Mond, Rodgers, \& Owen, 2007; Field et al., 2003; Hays et al., 2002; Konttinen, Haukkala, Sarlio-Lähteenkorva, Silventoinen, \& Jousilahti, 2009; Neumark-Sztainer et al., 2006; Solmi, Hatch, Hotopf, Treasure, \& Micali, 2014; Sonneville et al., 2013; TanofskyKraff et al., 2006, 2009). Our study confirmed this, but also quantified how the number of features an individual endorsed related to their BMI at two time points. We found that the number of features of BED was cumulatively associated with higher BMI. This means that although some features were relatively common in the community and had modest effect on BMI, endorsement of several features may have substantial implications for weight development.

The direction of causation between features of BED and weight gain deserves consideration. We could not definitely determine whether the investigated features preceded weight gain or vice versa: the features were assessed at age 22-27, but weight
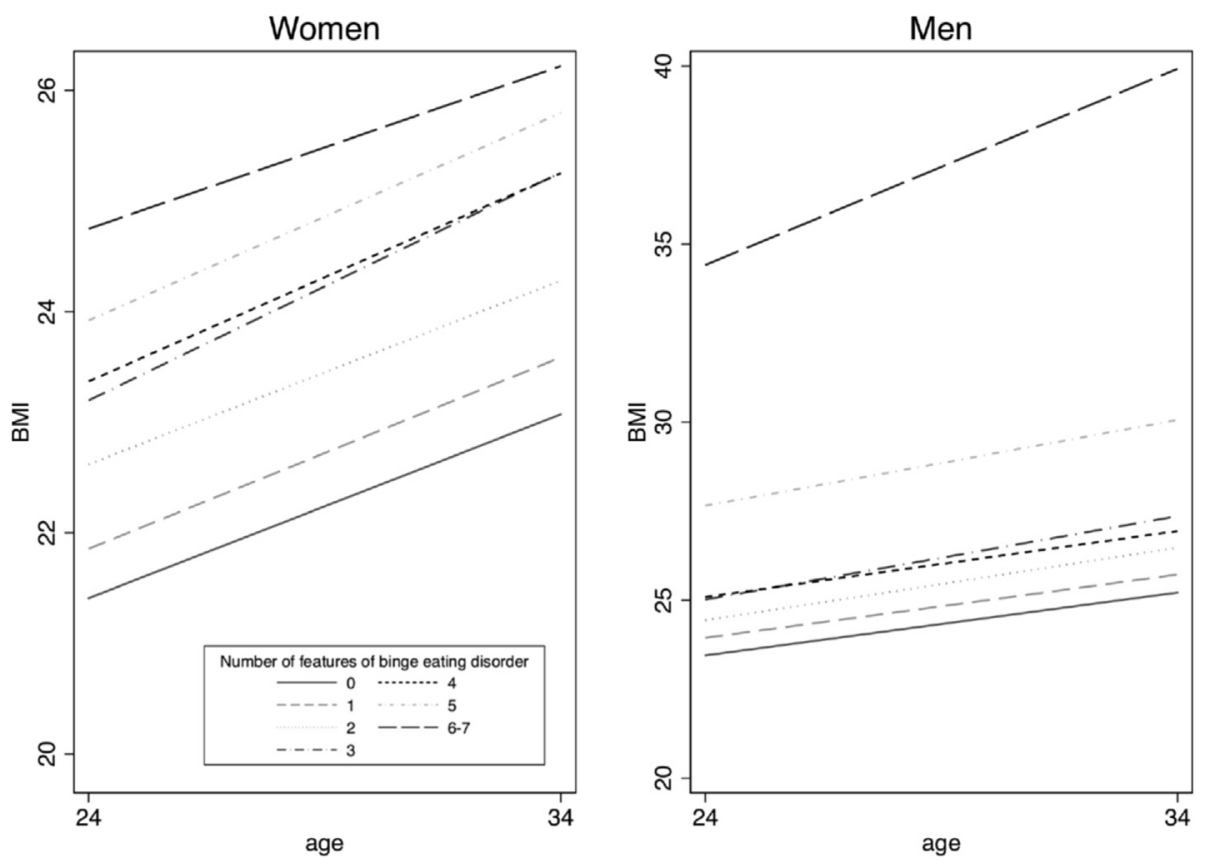

Fig. 3. Mean BMI at Wave 4 (mean age 24) and Wave 5 (mean age 34) according to number of features of binge eating disorder. 
trajectories of participants endorsing different numbers of features had already diverged at this time. Given that disordered eating behaviors are enduring patterns peaking in adolescence (Goldschmidt, Wall, Loth, Bucchianeri, \& Neumark-Sztainer, 2014; Keel, Baxter, Heatherton, \& Joiner TE, 2007; Neumark-Sztainer, Wall, Larson, Eisenberg, \& Loth, 2011; Tanofsky-Kraff et al., 2011), it is likely that some of our participants presented with features of BED already in their teenage years and that these contributed to their weight gain.

It is also possible that weight gain during adolescence influenced the emergence of features of BED. The social pressure to be thin is pronounced especially among teenage girls, and being heavier than their peers may have led to weight loss attempts and consequent loss of control over eating. Some features of BED, such as eating in secrecy and feeling guilty after overeating, may arise from the experience of not conforming to the body ideal of the social environment. Internalization of weight bias (i.e., blaming oneself for one's weight and resulting societal devaluation) may trigger binge eating (Puhl \& Suh, 2015). Eating has also been found to be a frequent behavioral response to the experience of weight stigmatization (Puhl \& Brownell, 2006). Consequently, it is likely that the relationship between features of BED and weight gain is bidirectional and some degree of shared etiology is likely.

We also found that features of BED were prospectively related to psychological distress. This is in line with previous research showing associations between depressive symptoms and emotional eating (Goldschmidt, Crosby, Engel et al., 2014; Konttinen, Männistö, Sarlio-Lähteenkorva, Silventoinen, \& Haukkala, 2010; Konttinen, Silventoinen, Sarlio-Lähteenkorva, Männistö, \& Haukkala, 2010; Ouwens, van Strien, van Leeuwe, \& van der Staak, 2009). Loss of control and binge eating have also been shown to predict increased psychological distress and onset of depressive symptoms in adolescents (Sonneville et al., 2013; Tanofsky-Kraff et al., 2011).

Notably, the association between features of BED and psychological distress remained statistically significant after controlling for BMI, a potential confounder of the relationship (Hryhorczuk, Sharma, \& Fulton, 2013; Konttinen et al., 2014; Singh, 2014). This suggests that features of BED may have adverse effects on wellbeing beyond the somatic and psychological effects of weight gain and obesity.

\section{Limitations}

Our study is subject to limitations inherent to observational studies, such as the possibilities of information bias, missing data bias, and confounding. All study variables were self-reported via questionnaire, which may cause reporting bias, particularly underreporting of weight and overreporting of height, potentially leading to underestimation of BMI (Larson, 2000). However, selfreported BMI has previously been shown to correlate closely with measured BMI in a subsample of this cohort (Mustelin, Silventoinen, Pietiläinen, Rissanen, \& Kaprio, 2009). Participants may also have interpreted the questions on eating-related behaviors and cognitions in different ways, which may have had an impact on the prevalences. To ascertain that the observed associations were not explained by clinical eating disorders, we repeated the analyses after excluding 182 women with any lifetime eating disorder. This did not attenuate the associations (data not shown; details available from the authors). We did not have information regarding eating-disorder diagnoses for the men in our cohort. Further, missing data due to attrition could affect the results. Our response rates were high throughout follow-up (Kaprio, 2006, 2013) and we found no evidence of selective attrition in respect to binge eating features between Waves 4 and 5 . Therefore, it is unlikely that attrition introduced systematic bias to our results. Our participants were young Finnish twins and results cannot necessarily be generalized to other age groups and ethnicities. Although twin boys (but not girls) were slightly leaner than their singleton peers in adolescence (Pietiläinen et al., 1999), we find it unlikely that the relationship between eating behaviors and weight development would differ between twins and singletons.

\section{Conclusions}

We found that in a longitudinal cohort of young adults, features of binge eating disorder, including both behavioral and psychological aspects, were cross-sectionally and prospectively associated with higher BMI and more psychological distress. Future studies should further examine the temporal and causal relationships between eating behaviors, mood, and weight gain in adolescence. In clinical practice, querying about binge-type eating behaviors and related cognitions may help to detect youth at increased risk for obesity and allow targeted prevention of weight gain.

\section{Conflict of interest statement}

LM, JK, AKR report no conflicts of interest. CB is a grant recipient from Shire, a consultant for Shire, and has served as a consultant for Ironshore.

\section{Acknowledgments}

The data collection and analysis was supported by the Academy of Finland (grants 141054, 265240, 263278 and 264146 to JK). LM received funding from the Finnish Medical Foundation and the Biomedicum Helsinki Foundation and CB from the Swedish Research Council (VR Dnr: 538-2013-8864). We thank Kauko Heikkilä, Anja Häppölä, and Pia Ruokolinna for their contribution in data collection and database management and Jaakko Koskela for assistance with figure preparation.

\section{References}

Abebe, D. S., Lien, L., Torgersen, L., \& von Soest, T. (2012). Binge eating, purging and non-purging compensatory behaviours decrease from adolescence to adulthood: A population-based, longitudinal study. BMC Public Health, 12, 32-245812-32.

Abraham, T. M., Massaro, J. M., Hoffmann, U., Yanovski, J. A., \& Fox, C. S. (2014) Metabolic characterization of adults with binge eating in the general population: The framingham heart study. Obesity (Silver Spring, Md.).

American Psychiatric Association. (2013). The diagnostic and statistical manual of mental disorders: DSM-5 (5th ed.). Washington D.C.: American Psychiatric Association.

Darby, A., Hay, P., Mond, J., Rodgers, B., \& Owen, C. (2007). Disordered eating behaviours and cognitions in young women with obesity: Relationship with psychological status. International Journal of Obesity (2005), 31(5), 876-882.

de Zwaan, M. (2001). Binge eating disorder and obesity. International Journal of Obesity and Related Metabolic Disorders : Journal of the International Association for the Study of Obesity, 25(Suppl. 1), S51-S55.

Field, A. E., Austin, S. B., Taylor, C. B., Malspeis, S., Rosner, B., Rockett, H. R. et al (2003). Relation between dieting and weight change among preadolescents and adolescents. Pediatrics, 112(4), 900-906.

Garner, D. M. (1991). Eating disorder inventory-2, professional manual. Odessa,FL: Psychological Assessment Resources.

Goldberg, D. P., Gater, R., Sartorius, N., Ustun, T. B., Piccinelli, M., Gureje, O., et al. (1997). The validity of two versions of the GHQ in the WHO study of mental illness in general health care. Psychological Medicine, 27(1), 191-197.

Goldschmidt, A. B., Crosby, R. D., Cao, L., Engel, S. G., Durkin, N., Beach, H. M., et al. (2014). Ecological momentary assessment of eating episodes in obese adults. Psychosomatic Medicine, 76(9), 747-752.

Goldschmidt, A. B., Crosby, R. D., Engel, S. G., Crow, S. J., Cao, L., Peterson, C. B., et al (2014). Affect and eating behavior in obese adults with and without elevated depression symptoms. The International Journal of Eating Disorders, 47(3) 281-286.

Goldschmidt, A. B., Loth, K. A., MacLehose, R. F., Pisetsky, E. M., Berge, J. M., \& Neumark-Sztainer, D. (2015). Overeating with and without loss of control: Associations with weight status, weight-related characteristics, and psychosocia 
health. The International Journal of Eating Disorders, 48(8), 1150-1157.

Goldschmidt, A. B., Wall, M. M., Loth, K. A., Bucchianeri, M. M., \& NeumarkSztainer, D. (2014). The course of binge eating from adolescence to young adulthood. Health Psychology : Official Journal of the Division of Health Psychology, American Psychological Association, 33(5), 457-460.

Grilo, C. M., White, M. A., \& Masheb, R. M. (2009). DSM-IV psychiatric disorder comorbidity and its correlates in binge eating disorder. The International Journal of Eating Disorders, 42(3), 228-234.

Haedt-Matt, A. A., \& Keel, P. K. (2011). Revisiting the affect regulation model of binge eating: A meta-analysis of studies using ecological momentary assessment. Psychological Bulletin, 137(4), 660-681.

Hay, P. J., Mond, J., Buttner, P., \& Darby, A. (2008). Eating disorder behaviors are increasing: Findings from two sequential community surveys in south Australia. PLoS One, 3(2), e1541.

Hays, N. P., Bathalon, G. P., McCrory, M. A., Roubenoff, R., Lipman, R., \& Roberts, S. B. (2002). Eating behavior correlates of adult weight gain and obesity in healthy women aged 55-65 y. The American Journal of Clinical Nutrition, 75(3), 476-483.

Hryhorczuk, C., Sharma, S., \& Fulton, S. E. (2013). Metabolic disturbances connecting obesity and depression. Frontiers in Neuroscience, 7, 177.

Hudson, J. I., Hiripi, E., Pope, H. G., Jr., \& Kessler, R. C. (2007). The prevalence and correlates of eating disorders in the National Comorbidity Survey Replication. Biological Psychiatry, 61(3), 348-358.

Javaras, K. N., Pope, H. G., Lalonde, J. K., Roberts, J. L., Nillni, Y. I., Laird, N. M., et al. (2008). Co-occurrence of binge eating disorder with psychiatric and medical disorders. The Journal of Clinical Psychiatry, 69(2), 266-273.

Kaprio, J. (2006). Twin studies in Finland 2006. Twin Research and Human Genetics : The Official Journal of the International Society for Twin Studies, 9(6), 772-777.

Kaprio, J. (2013). The Finnish twin cohort study: An update. Twin Research and Human Genetics : The Official Journal of the International Society for Twin Studies, 16(1), 157-162

Kaprio, J., Pulkkinen, L., \& Rose, R. J. (2002). Genetic and environmental factors in health-related behaviors: Studies on Finnish twins and twin families. Twin Research : The Official Journal of the International Society for Twin Studies, 5(5), 366-371.

Kärkkäinen, U., Mustelin, L., Raevuori, A., Kaprio, J., \& Keski-Rahkonen, A. (2016). Ideals versus reality: Are weight ideals associated with weight change in the population? Obesity (Silver Spring, Md.), 24(4), 947-953.

Keel, P. K., Baxter, M. G., Heatherton, T. F., \& Joiner, T. E., Jr. (2007). A 20-year longitudinal study of body weight, dieting, and eating disorder symptoms. Journal of Abnormal Psychology, 116(2), 422-432.

Kessler, R. C., Berglund, P. A., Chiu, W. T., Deitz, A. C., Hudson, J. I., Shahly, V., et al (2013). The prevalence and correlates of binge eating disorder in the world health organization world mental health surveys. Biological Psychiatry, 73(9), 904-914.

Konttinen, H., Haukkala, A., Sarlio-Lahteenkorva, S., Silventoinen, K., \& Jousilahti, P. (2009). Eating styles, self-control and obesity indicators. The moderating role of obesity status and dieting history on restrained eating. Appetite, 53(1), 131-134.

Konttinen, $\mathrm{H}$., Kiviruusu, O., Huurre, T., Haukkala, A., Aro, H., \& Marttunen, M. (2014). Longitudinal associations between depressive symptoms and body mass index in a 20-year follow-up. International Journal of Obesity (2005), 38(5), 668-674.

Konttinen, H., Männistö, S., Sarlio-Lähteenkorva, S., Silventoinen, K., \& Haukkala, A. (2010). Emotional eating, depressive symptoms and self-reported food consumption. A population-based study. Appetite, 54(3), 473-479.

Konttinen, H., Silventoinen, K., Sarlio-Lähteenkorva, S., Männistö, S., \& Haukkala, A. (2010). Emotional eating and physical activity self-efficacy as pathways in the association between depressive symptoms and adiposity indicators. The American Journal of Clinical Nutrition, 92(5), 1031-1039.

Langkamp, D. L., Lehman, A., \& Lemeshow, S. (2010). Techniques for handling missing data in secondary analyses of large surveys. Academic Pediatrics, 10(3), $205-210$.

Larson, M. R. (2000). Social desirability and self-reported weight and height. International Journal of Obesity and Related Metabolic Disorders : Journal of the International Association for the Study of Obesity, 24(5), 663-665.

Leehr, E. J., Krohmer, K. Schag, K., Dresler, T., Zipfel, S., \& Giel, K. E. (2015). Emotion regulation model in binge eating disorder and obesity-A systematic review. Neuroscience and Biobehavioral Reviews, 49, 125-134.

Munsch, S., Meyer, A. H., Quartier, V., \& Wilhelm, F. H. (2012). Binge eating in binge eating disorder: A breakdown of emotion regulatory process? Psychiatry Research, 195(3), 118-124.

Mustelin, L., Raevuori, A., Hoek, H. W., Kaprio, J., \& Keski-Rahkonen, A. (2015)
Incidence and weight trajectories of binge eating disorder among young women in the community. The International Journal of Eating Disorders, 48(8), 1106-1112.

Mustelin, L., Silventoinen, K., Pietiläinen, K., Rissanen, A., \& Kaprio, J. (2009). Physical activity reduces the influence of genetic effects on BMI and waist circumference: A study in young adult twins. International Journal of Obesity (2005, 33(1), 29-36.

Neumark-Sztainer, D., Wall, M., Guo, J., Story, M., Haines, J., \& Eisenberg, M. (2006). Obesity, disordered eating, and eating disorders in a longitudinal study of adolescents: How do dieters fare 5 years later? Journal of the American Dietetic Association, 106(4), 559-568.

Neumark-Sztainer, D., Wall, M., Larson, N. I., Eisenberg, M. E., \& Loth, K. (2011). Dieting and disordered eating behaviors from adolescence to young adulthood: Findings from a 10-year longitudinal study. Journal of the American Dietetic Association, 111(7), 1004-1011.

Ouwens, M. A., van Strien, T., van Leeuwe, J. F. \& van der Staak, C. P. (2009). The dual pathway model of overeating. Replication and extension with actual food consumption. Appetite, 52(1), 234-237.

Penninkilampi-Kerola, V., Miettunen, J., \& Ebeling, H. (2006). A comparative assessment of the factor structures and psychometric properties of the GHQ-12 and the GHQ-20 based on data from a Finnish population-based sample. Scandinavian Journal of Psychology, 47(5), 431-440.

Pietiläinen, K. H., Kaprio, J., Rissanen, A., Winter, T., Rimpelä, A., Viken, R. J., et al. (1999). Distribution and heritability of BMI in finnish adolescents aged 16y and 17y: A study of 4884 twins and 2509 singletons. International Journal of Obesity and Related Metabolic Disorders : Journal of the International Association for the Study of Obesity, 23(2), 107-115.

Preti, A., Girolamo, G., Vilagut, G., Alonso, J., Graaf, R., Bruffaerts, R., et al. (2009). The epidemiology of eating disorders in six european countries: Results of the esemed-wmh project. Journal of Psychiatric Research, 43(14), 1125-1132.

Puhl, R. M., \& Brownell, K. D. (2006). Confronting and coping with weight stigma: An investigation of overweight and obese adults. Obesity (Silver Spring, Md.), 14(10), 1802-1815.

Puhl, R., \& Suh, Y. (2015). Stigma and eating and weight disorders. Current Psychiatry Reports, 17(3), 552-015-0552-6.

Singh, M. (2014). Mood, food, and obesity. Frontiers in Psychology, 5, 925.

Smink, F. R., van Hoeken, D., Oldehinkel, A. J., \& Hoek, H. W. (2014). Prevalence and severity of DSM-5 eating disorders in a community cohort of adolescents. The International Journal of Eating Disorders, 47(6), 610-619.

Solmi, F., Hatch, S. L., Hotopf, M., Treasure, J., \& Micali, N. (2014). Prevalence and correlates of disordered eating in a general population sample: The south east london community health (SELCoH) study. Social Psychiatry and Psychiatric Epidemiology, 49(8), 1335-1346.

Sonneville, K. R., Horton, N. J., Micali, N., Crosby, R. D., Swanson, S. A., Solmi, F., et al. (2013). Longitudinal associations between binge eating and overeating and adverse outcomes among adolescents and young adults: Does loss of control matter? JAMA Pediatrics, 167(2), 149-155.

Striegel-Moore, R. H., Cachelin, F. M., Dohm, F. A., Pike, K. M., Wilfley, D. E., \& Fairburn, C. G. (2001). Comparison of binge eating disorder and bulimia nervosa in a community sample. The International Journal of Eating Disorders, 29(2), $157-165$.

Tanofsky-Kraff, M., Cohen, M. L., Yanovski, S. Z., Cox, C., Theim, K. R., Keil, M., et al. (2006). A prospective study of psychological predictors of body fat gain among children at high risk for adult obesity. Pediatrics, 117(4), 1203-1209.

Tanofsky-Kraff, M., Goossens, L., Eddy, K. T., Ringham, R., Goldschmidt, A. Yanovski, S. Z., et al. (2007). A multisite investigation of binge eating behaviors in children and adolescents. Journal of Consulting and Clinical Psychology, 75(6), 901-913.

Tanofsky-Kraff, M., Shomaker, L. B., Olsen, C., Roza, C. A., Wolkoff, L. E. Columbo, K. M., et al. (2011). A prospective study of pediatric loss of control eating and psychological outcomes. Journal of Abnormal Psychology, 120(1), $108-118$.

Tanofsky-Kraff, M., Yanovski, S. Z., Schvey, N. A., Olsen, C. H., Gustafson, J., \& Yanovski, J. A. (2009). A prospective study of loss of control eating for body weight gain in children at high risk for adult obesity. The International Journal of Eating Disorders, 42(1), 26-30.

Williams, R. L. (2000). A note on robust variance estimation for cluster-correlated data. Biometrics, 56(2), 645-646.

Wolfe, B. E., Baker, C. W., Smith, A. T., \& Kelly-Weeder, S. (2009). Validity and utility of the current definition of binge eating. The International Journal of Eating Disorders, 42(8), 674-686. 